\title{
Impact of pollutants in the energy sector on the environment and technologies for treating liquid and solid waste from power plants
}

\author{
Irina Alina Chera-Anghel ${ }^{1 *}$, Loredana Popescu $^{2}$, Florentina Condrea $^{3}$ \\ ${ }^{1}$ Ph.D. student, Research Assistant, Energy Research and Modernization Institute - ICEMENERG, \\ Bucharest, Romania \\ ${ }^{2}$ Senior researcher, Energy Research and Modernization Institute - ICEMENERG, Bucharest, \\ Romania \\ ${ }^{3}$ Senior researcher, Energy Research and Modernization Institute - ICEMENERG, Bucharest, \\ Romania
}

\begin{abstract}
The main pollutants in the soil are composed of ash, clay, and calcium sulfur, which results from the desulfurization of flue gases. However, the infiltration of liquid fuels and lubricants, as well as transformation oil, may be neglected. Liquid residues result from several technological processes. The main source of pollution is the water treatment process that must be used in the water-steam circuit. Another important source of liquid residues is the cooling process of the thermal agent. A third major source of water pollution is the flue gas desulphurization process and the transport of slag and ash. Thus, it should not be neglected that power plants are large industrial installations, which require permanent maintenance, liquid residues resulting from cleaning operations of various equipment. To have the technology for treatment, disposal and storage of high-efficiency waste, we must take into account the following factors: the volume and type of waste, their properties, the likely evolution of the installation, the volume of waste generated by it, treatment possibilities and even limits imposed by environmental regulations.
\end{abstract}

\section{Introduction}

The energy sector, worldwide, through the complexity of the installations and technological processes, the characteristics of the raw materials, which are entering the process, and of the resulting waste, is one of the most important industrial processes, whose impact on the environment is major. Electricity production is a technological process efficient, fully conditions are considered the impacts on the environment. The multitude of chemical reactions, which take place in all the technological processes in the power plant, changes the characteristics of the materials, entered into the contour, thus generating residues, which must be stored, in-situ, or released into the environment, polluting, to some extent, all environmental factors.

*Corresponding author: irina.chera@icemenerg.ro; irina.alina.chera@gmail.com. 
The analysis of the pollution generated by power plants should take into account the following sources of pollution: solid particulate air pollution and toxic gases $\left(\mathrm{SO}_{2}\right.$, $\mathrm{NO}_{2}, \mathrm{NO}, \mathrm{CO}, \mathrm{CO}_{2}, \mathrm{NH}_{3}, \mathrm{HCl}$, etc.) and evaporation, the pollution discharge areas wastewater, thermal emission pollution, soil pollution, pollution caused by hydro-technical circuits, which can become sources of air pollution, by evaporation, at the cooling towers pollution caused by slag and ash deposits, which contaminate the soil and groundwater, these are the most important sources of pollution that we will present in this article.

At the level of thermoelectric power stations, several sources of pollution can be identified, such as transport installations; preparation and storage of fuels; combustion plants; water supply installations; technological water treatment plants; wastewater treatment and neutralization systems and associated sewers; slag deposits, ash, and byproducts of neutralization reactions.

The entries in the contour of the chemical balance, similar to a mass balance, are the fuel; limestone, necessary for $\mathrm{SO}_{2}$ emission control; water, necessary for the production of steam, cooling of the thermal circuit and other inherent uses; ammonia and catalysts, necessary to control $\mathrm{N}$ emission; different chemicals used in water treatment, softening and neutralization processes, as well as in maintenance operations. electricity supply, it is found that this process is not efficient, to a large extent.

The chemical substances, frequently used in the technological flow of some classic power plants, are coagulants, for water pretreatment; sulfuric acid; $\mathrm{HCl}$; caustic soda; ammonia; sodium phosphates, and corrosion inhibitors. In addition to these substances, various acids, bases, and organic substances are also used to perform periodic maintenance operations, including washing of heat exchangers, on the water circulation side, of air preheaters, assuming the risk of sulfate deposition. of ammonium is high, of the electrodes of deposition of electro filters, etc.

The useful results from the outline of the global balance of a thermal power plant are, of course, electricity and, finally, thermal energy, to which can be added certain quantities of ammonium salts, usable as chemical fertilizers, gypsum and various agglomerates, usable in building materials in the industry, as well as certain amounts of sulfur and sulfuric acid, if the recovery is more complex. However, there is a large amount of waste, which is a source of pollution, for all environmental factors, whether these substances are discharged into the atmosphere or emissions, or stored in situ.

So to remove these sources of pollution, this article presents some treatments that are applied to remove this waste from the energy sector, to protect the environment.

\section{Sources of pollutants from power plants}

From ecologically, there are important differences between the various categories of pollutants. Thus, they differ:

- pollutants by direct action on the human body, such as nitrogen oxides, sulfur oxides, carbon monoxide, and some heavy metals;

- pollutants with direct action on vegetation, such as sulfur dioxide and combinations of chlorine with hydrogen;

- pollutants underlying the formation of acids, such as $\mathrm{SO}_{2}, \mathrm{SO}_{3}, \mathrm{NO}$, and $\mathrm{NO}_{2}$;

- pollutants that become factors of influence of the climate, such as $\mathrm{CO}_{2}, \mathrm{NO}_{2}$, and $\mathrm{N}_{2} \mathrm{O}$, as well as important factors in accentuating the greenhouse effect or contributing to the destruction of stratospheric ozone. 
The main process in the plant, that of the combustion of the fuel, is a major source of air pollution. Besides the pollution of the atmosphere, the combustion of the fuel, as well as all the processes that contribute to the development of the main process, are important sources of liquid and solid waste, which can pollute, severely, the water and the soil. Quantitatively, the most important solid wastes from a power plant are slag and ash, resulting from the combustion of fuel and calcium salts, resulting from the process of reducing sulfur oxide emissions [1].

Even though slag and ash storage requires considerable economic effort, soil pollution generated by fuel preparation facilities, fuel depots, fuels, lubricants, various chemicals should not be neglected. Also, the residues resulting from the electrical installations of the plants should not be neglected. The soil can be polluted by the leakage of transformer oil, the storage of ceramic materials, and some more or less oxidized metal waste.

Another important source of liquid waste is the process of treating the water used in the thermal circuit. Thus, the wastewater, resulting from this process, contains traces of the reagents used, as well as acid and basic demineralize. Another important source of polluted water is the cooling circuit, as well as the leakage from the main circuit. A third important source of water pollution is represented by the installations for the treatment of gaseous emissions, in particular for the treatment of the emission of sulfur oxides, as well as the installations for the transport of slag and ash.

Water vapors, as well as water droplets, driven by the flow of vapors, are a source of local, pollution of the atmosphere. Continuous evaporation of a flow of water causes the concentration of salts in the coolant to increase. When the solution reaches saturation, the salts can settle on the condenser tubing and other cooling circuit equipment. Sedimentation can be avoided by introducing chemical inhibitors or by periodically purging an amount of cooling water. The discharge of purged water, with a high concentration of salts, represents a second pollutant residue, resulting from the cooling circuit. Regardless of whether the cooling is performed in an open or closed circuit, the temperature of the cooling water favors the development of microorganisms, which can clog the condenser pipes.

To avoid the exaggerated development of these microorganisms, the cooling water is chlorinated, a certain amount of chlorine can be found in the water directed to the emitter or in the purge. Due to the high toxicity of chlorine, at least in the case of open-circuit power plants, it is necessary to de-chlorinate the cooling water. Relatively large amounts of contaminated wastewater result from the ash and slag transport facilities, obviously in the case of solid fuel combustion. The amount of ash and slag is strictly dependent, at the same amount of energy provided, on the concentration of the coal tailings. It can be appreciated, however, that about $20 \%$, of the total of the solid substance, is retained, in the form of slag, at the base of the outbreak, $4 \%$, in the form of flying ashes, at the exit of the gases from the economizer, the rest of $76 \%$ being retained by electro filter or filter bag.

The retained ash from the flue gas can be transported hydraulically, in the form of sludge, or pneumatically, in the case of new plants, the latter option is preferred. The slag, retained at the base of the outbreak, is cooled by a continuous flow of water. Periodically, the slurry, thus formed, is transported to the final depot or an intermediate storage area. 
Under these conditions, the resulting water is heavily polluted with suspended solids, dissolved salts, and heavy metals, the $\mathrm{pH}$ of the residual water can vary within very wide limits. Some of the wastewater used in the transport of slag and ash are listed in Table 1.

Table 1. The level of pollutants in the water used to transport the slag and ash

\begin{tabular}{|c|c|c|c|c|c|}
\hline \multirow{2}{*}{ No. crt. } & \multirow{2}{*}{ Substance } & \multicolumn{2}{|c|}{$\begin{array}{l}\text { Water transport slag from } \\
\text { the bottom of the furnace }\end{array}$} & \multicolumn{2}{|c|}{ Water transport fly ash } \\
\hline & & $\operatorname{minim}$ & Maxim & $\operatorname{minim}$ & Maxim \\
\hline 1 & Water flow & $18 \mathrm{~m}^{3 /} \min$ & $88 \mathrm{~m}^{3 /} \min$ & $11.5 \mathrm{~m}^{3 /} \mathrm{min}$ & $33.2 \mathrm{~m}^{3 /} \min$ \\
\hline 2 & $\mathrm{pH}$ & 4.1 & 7.9 & 3.6 & 6.3 \\
\hline 3 & $\begin{array}{l}\text { Dissolved } \\
\text { solid }\end{array}$ & $70 \mathrm{mg} / 1$ & $405 \mathrm{mg} / \mathrm{l}$ & $142 \mathrm{mg} / 1$ & $821 \mathrm{mg} / \mathrm{l}$ \\
\hline 4 & $\begin{array}{l}\text { Solid } \\
\text { substance in } \\
\text { suspension }\end{array}$ & $5.2 \mathrm{mg} / \mathrm{l}$ & $658 \mathrm{mg} / \mathrm{l}$ & $2.2 \mathrm{mg} / \mathrm{l}$ & $258 \mathrm{mg} / \mathrm{l}$ \\
\hline 5 & Aluminum & $0.5 \mathrm{mg} / 1$ & $8.0 \mathrm{mg} / \mathrm{l}$ & $3.2 \mathrm{mg} / \mathrm{l}$ & $8.8 \mathrm{mg} / \mathrm{l}$ \\
\hline 6 & $\begin{array}{c}\text { Ammonia (in } \\
\text { nitrogen } \\
\text { equivalent) }\end{array}$ & $0.02 \mathrm{mg} / \mathrm{l}$ & $0.32 \mathrm{mg} / 1$ & $0.04 \mathrm{mg} / 1$ & $0.43 \mathrm{mg} / 1$ \\
\hline 7 & Arsenic & $0.003 \mathrm{mg} / \mathrm{l}$ & $0.16 \mathrm{mg} / 1$ & $0.006 \mathrm{mg} / 1$ & $0.024 \mathrm{mg} / \mathrm{l}$ \\
\hline 8 & Cadmium & $0.002 \mathrm{mg} / \mathrm{l}$ & $0.003 \mathrm{mg} / \mathrm{l}$ & $0.024 \mathrm{mg} / \mathrm{l}$ & $0.053 \mathrm{mg} / \mathrm{l}$ \\
\hline 9 & Chlorine & $6 \mathrm{mg} / 1$ & $16 \mathrm{mg} / \mathrm{l}$ & $6 \mathrm{mg} / \mathrm{l}$ & $15 \mathrm{mg} / \mathrm{l}$ \\
\hline 10 & Copper & $0.02 \mathrm{mg} / \mathrm{l}$ & $0.15 \mathrm{mg} / \mathrm{l}$ & $0.17 \mathrm{mg} / \mathrm{l}$ & $0.46 \mathrm{mg} / 1$ \\
\hline 11 & Cyanide & $0.02 \mathrm{mg} / 1$ & $0.02 \mathrm{mg} / \mathrm{l}$ & $0.02 \mathrm{mg} / \mathrm{l}$ & $0.02 \mathrm{mg} / \mathrm{l}$ \\
\hline 12 & Iron & $1.8 \mathrm{mg} / \mathrm{l}$ & $12 \mathrm{mg} / 1$ & $0.34 \mathrm{mg} / \mathrm{l}$ & $6.7 \mathrm{mg} / \mathrm{l}$ \\
\hline 13 & Lead & $0.01 \mathrm{mg} / 1$ & $0.04 \mathrm{mg} / 1$ & $0.02 \mathrm{mg} / \mathrm{l}$ & $0.3 \mathrm{mg} / 1$ \\
\hline 14 & Magnesium & $0.4 \mathrm{mg} / 1$ & $9.4 \mathrm{mg} / \mathrm{l}$ & $9.5 \mathrm{mg} / 1$ & $21 \mathrm{mg} / 1$ \\
\hline 15 & Mercury & $0.0003 \mathrm{mg} / \mathrm{l}$ & $0.0027 \mathrm{mg} / \mathrm{l}$ & $0.0003 \mathrm{mg} / \mathrm{l}$ & $0.0007 \mathrm{mg} / \mathrm{l}$ \\
\hline 16 & Sulfates & $42 \mathrm{mg} / \mathrm{l}$ & $81 \mathrm{mg} / \mathrm{l}$ & $241 \mathrm{mg} / \mathrm{l}$ & $442 \mathrm{mg} / 1$ \\
\hline 17 & Zinc & $0.02 \mathrm{mg} / \mathrm{l}$ & $0.17 \mathrm{mg} / 1$ & $1.2 \mathrm{mg} / 1$ & $2.8 \mathrm{mg} / 1$ \\
\hline
\end{tabular}

The high concentration of the solid suspensions requires, for the majority of the power stations, in which coal is burned, the creation of artificial lakes, in which the solid substance settles, the resulting water can be reused or discharged. Sulfur oxide emission reduction plants, whether based on wet or dry technologies, are generating polluted wastewater.

The amount of wastewater is significantly higher in the case of wet technologies, but also the dry and quasi-dried technologies can be considered as generating wastewater, polluted, as long as the reaction by-products are transported to the storage site through a flow of waste. the water. Frequently, the water resulting from the desulphurization processes, especially from the wet ones, has a high content of dissolved and suspended solids and are saturated with calcium sulfate. Because coal also contains certain amounts of chlorine and fluoride, which are quickly retained during the wet desulphurization process, the wastewater will also contain chemical combinations of these substances.

Also, the content of unreacted additive, usually calcium carbonate, as well as certain heavy metal content, should not be neglected. Typical concentrations of pollutants in the water resulting from the process of wet secondary desulphurization are given in Table 2 [1]. 
Table 2. Typical concentrations of the pollutants in the water from the wet desulfurization systems

\begin{tabular}{|c|c|c|c|c|c|}
\hline Substance & $\begin{array}{c}\text { Concentration } \\
(\mathbf{m g} / \mathbf{l})\end{array}$ & Substance & $\begin{array}{c}\text { Concentration } \\
(\mathbf{m g} / \mathbf{l})\end{array}$ & Substance & $\begin{array}{c}\text { Concentration } \\
(\mathbf{m g} / \mathbf{l})\end{array}$ \\
\hline Aluminum & $0.02 \div 2.0$ & Lead & $0.02 \div 0.52$ & Chlorine & $421 \div 33000$ \\
\hline Arsenic & $0.005 \div 1.8$ & Magnesium & $4.1 \div 750$ & Fluorine & $0.6 \div 58$ \\
\hline Calcium & $181 \div 2600$ & Mercury & $0.0005 \div 0.07$ & Sulphites & $0.9 \div 3500$ \\
\hline Chromium & $0.014 \div 0.5$ & Sodium & $11 \div 29000$ & Sulphates & $601 \div 35000$ \\
\hline Copper & $0.003 \div 0.56$ & Zinc & $0.02 \div 0.59$ & $\begin{array}{c}\text { Total } \\
\text { dissolved } \\
\text { solids }\end{array}$ & $2801 \div 92500$ \\
\hline
\end{tabular}

If, in addition to the previous observations, the ones related to the relatively large quantities of wastewater, resulting from the process of preparing the fuel, directly or indirectly, as well as those from the maintenance operations, which flow through the drainage systems, the necessity arises achieving a strict control of the wastewater, at the level of the whole plant.

\section{TREATMENT OF LIQUID AND SOLID WASTE}

\subsection{Treatment of liquid waste}

Numerous technologies can be used to treat the liquid residues of the thermoelectric power stations, to eliminate the suspended solids, separate and retaining the petroleum residues, resulting from the loss of fuel or lubricants, the dechlorination, the retention of the heavy metal residues. Some of the commonly used techniques are presented in the following sections.

\subsubsection{Elimination of solid suspensions}

The oldest and most widespread for the elimination of solid suspensions is that of the wastewater decanting, in the settling basins. These tanks must be so designed as to provide residence time necessary to carry out the physical phenomenon of gravitational settling.

In the current installations, the decanting process is associated with coagulation and flocculation processes, both for reducing the time spent in the reagent, in the raw water, and for reducing the size of the treatment plants. In many situations, coagulation and flocculation are not independent technological processes but are embedded in the constructive structure and technological flow of the decanter $[2,3]$.

The fine particles create colloidal suspensions in water. The kinetics of colloidal dispersion is influenced by several parameters, such as [2]:

- $\quad$ the nature of the two-phase environment; 
- the temperature at which the decanting, coagulation, flocculation processes take place;

- colloid concentration;

- the presence of substances that act as inhibitors;

- the intensity of agitation;

- the residence time of the mixture of water and reagent, in the treatment tanks.

The initiation and development of the decanting, coagulation and flocculation processes can be characterized by a dimensionless parameter, called the Camp number [2]

$$
G=K \cdot t, \text { where: }
$$

- $\mathrm{G}$ is the velocity gradient, and $\mathrm{t}$ represents the residence time.

The velocity gradient is defined as the difference between the velocities of two adjacent liquid layers, is temperature dependent, through the dynamic viscosity coefficient, and is one of the most important parameters of the coagulation and flocculation processes. The velocity gradient is defined as the difference between the velocities of two adjacent liquid layers, is temperature dependent, through the dynamic viscosity coefficient, and is one of the most important parameters of the coagulation and flocculation processes. The average velocity gradient, corresponding to the turbulent regime, can be calculated with the relation [2]:

$$
G=\sqrt{\frac{P}{V \cdot \mu}}\left(s^{-1}\right), \text { where: }
$$

- $\mathrm{P}$ is the power dissipated for shaking a volume;

- V of water and $\mu$ is the coefficient of dynamic viscosity.

Flocculation is a slow kinetic process so that the agitation does not have to be violent, to allow the formation of micro flocs, and then their volume increase. Unlike flocculation, coagulation is an irreversible process, which requires small times for the reaction to be complete under intense agitation. Under these conditions, the adoption of a certain value for the Camp number depends on the type of reaction, the time it takes, the energy consumption, the nature of the coagulant, and the amount of coagulant. The station time and Camp number are also chosen according to the clarification technology, which is used subsequently $[4,5]$.

\subsubsection{Separation of oils}

Lubricating oils and greases, for the maintenance of central mechanical equipment, pollute the drain water in general and sewage network. Other sources of pollution, of this type, are the liquid fuel storage facilities, as well as the transformers in the power outlet station in the power plant. All leaks, which may be contaminated with such residues, must be collected and treated in a separation facility. Because most oils have less specific weight than water, the separation consists, in fact, in the temporary, temporary retention of 
contaminated water, in some separation tanks. In Figure 1 a schematic representation is given of an oil separator, the gravity-type construction.

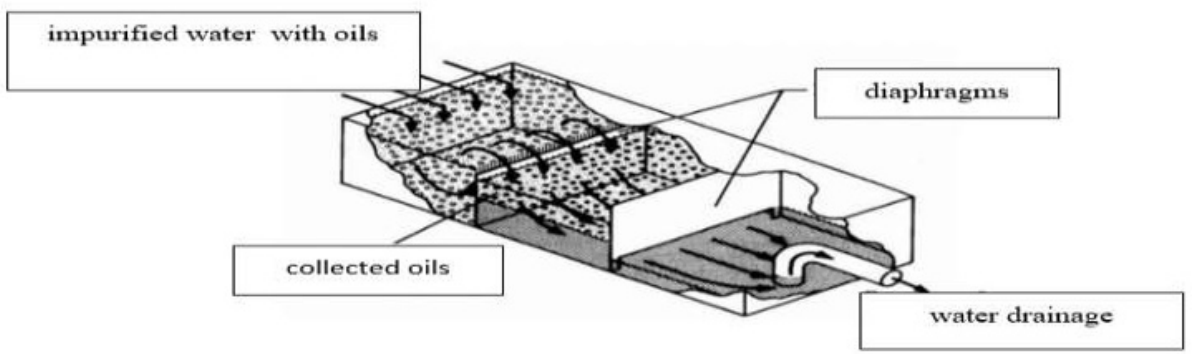

Fig. 1. The principle of gravitational separation of oils from wastewater

To prevent the oil residue from leaking, simultaneously with the water, when it is discharged from the separator, the separator is provided with diaphragms and with the possibility of partial discharge. The collected oil is pumped outside at certain intervals using portable pumps. When the residual oil is finely dispersed in water, forming emulsions, and the limits imposed on the effluent pollution level are very drastic, fusion oil separators can be used. These separators are also of gravitational type, except that some elements are used, which cause the agglomeration of the small oil particles. The agglomeration process continues until the particle sizes are large enough to achieve effective gravitational separation.

\subsubsection{Dechlorination and reduce the heavy metal content}

In addition to the processes described above, the wastewater from power plants can browse the dechlorination process steps, evaporation, and distillation, crystallization, and disposal of heavy metals $[1,6,7]$. Current standards impose limits on the quality of the water of chlorine compounds reduced, precise control is required so that the presence of these compounds in the wastewater to be discharged into the environment. In power plants, residual chlorine can exist both in the water in the cooling circuit, either closed or open, and in the wastewater resulting from the processes of treating the thermal agent and transporting the solid pollutants. Dechlorination can be achieved by the addition of sulfur dioxide, sodium sulfite, or sodium metabisulphite. Due to the high flow rates of water in the cooling circuit, it is preferable to use the cheapest additive such as $\mathrm{SO}_{2}$. In certain situations, activated carbon can also be used $[8,9]$.

The chemical reactions specific to the dechlorination process are the following:

$$
\begin{gathered}
\mathrm{SO}_{2}+\mathrm{H}_{2} \mathrm{O} \rightarrow \mathrm{H}_{2} \mathrm{SO}_{4} \\
\mathrm{H}_{2} \mathrm{SO}_{3}+\mathrm{HOCl} \rightarrow \mathrm{H}_{2} \mathrm{SO}_{4}+\mathrm{HCl} \\
\mathrm{NH}_{2} \mathrm{Cl}+\mathrm{H}_{2} \mathrm{SO}_{3} \rightarrow \mathrm{NH}_{4} \mathrm{H}_{2} \mathrm{SO}_{4}+\mathrm{HCl}
\end{gathered}
$$


All of these reactions have very fast kinetics. From a stoichiometric point of view, 0.9 ppm $\mathrm{SO}_{2}$ is required to retain $1 \mathrm{ppm}$ chlorine.

The equipment used to supply the $\mathrm{SO}_{2}$ system is similar to that used for liquid chlorine supply. Keeping the storage containers at a temperature of $22 \div 28^{\circ} \mathrm{C}$ avoids relaying the gas into the pipelines (the boiling temperature of $\mathrm{SO}_{2}$ is $-7^{\circ} \mathrm{C}$, at atmospheric pressure). If the gas consumption is high, several containers can be used at the same time, the pressure reduction in them not being large enough that the relic phenomenon occurs.

Due to the toxicity of sulfur dioxide, several measures must be taken to prevent contamination of the enclosures in which the installation is located. First of all, it is preferable to install, in separate rooms, the pressurized part and the vacuum part of the installation. The rooms must be equipped with exhaust fans, installed close to the floor because sulfur dioxide is heavier than air. It is also preferable to install $\mathrm{SO}_{2}$ detectors, whose transducers are also installed near the floor of the room.

Metals can be removed from wastewater by various processes, such as alkaline precipitation, sulfur precipitation or ion exchange. Alkaline precipitation uses reagents, such as $\mathrm{CaO}$ or $\mathrm{NaOH}$, leading to the formation of heavy metal hydroxides. Because in such reactions there are relatively few metals, alkaline precipitation is rarely used in the technological flow of wastewater treatment plants. It is preferable to use the iron coprecipitation process $[1,10]$.

In the first step of the process, the $\mathrm{pH}$ of the wastewater is corrected, up to that value at which the reaction between the metals, which is about to be eliminated, and the iron salts have good kinetics. After the addition of ferric chloride and an oxidation process, ferrous sulfate is formed, which precipitates in the presence of flocculating agents. The dissolved and suspended metals are retained by the flammable ferrous sulfate flakes at the bottom of the reaction and decanting chamber.

\subsection{Solid waste treatment}

The adoption of a particular system or technology for the treatment, disposal, and storage of solid residues must take into account the following factors: volume and type of residues, their properties, possible restrictions between residual substances and those of the site, the environmental impact of the deposit, the environmental norms in force, but also factors of prognosis, such as the probable evolution of the boiler, of the volume of residues generated by it, of the possibilities of treatment and even of the limits imposed, by the environmental norms $[10,11]$.

The evaluation of the operational factors refers to the following aspects:

- types of solid residues generated; these may change, during the operation of the boiler, in particular, due to the adoption of new technologies for the treatment of the flue gases, but also due to the change of the combustion technique or the type of fuel;

- the weight of each type of solid residue; these weights can change over time due to the use of different qualitative fuels or mixtures of fuels and due to the modification of desulfurization techniques;

- if these changes are long-term changes, the weight of each type of residue may also differ in the short term, the effect of the dynamic character of the pregnancy; 
- the location of the points of discharge and storage, temporary, each type of solid residue;

- the operating procedures of the boiler and its load curve;

- $\quad$ the expected life of the plant.

Regarding solid waste properties, interested in a wide range of physical and chemical properties, from wettability, and to potentially toxic gases, through spontaneous release or by any processes of gases. The adoption of technical solutions must take into account all these properties and, also, the fact that they can change over time.

The restrictions imposed on the solid waste storage site are related to the following issues:

- the actual use of the land in question;

- possibility of flooding, drainage or stagnation of water;

- the proximity to the natural habitat of the different species of animals, as well as the risk that the deposit for each species may present;

- the storage capacity of the deposit;

- the topography of the place and how favorable it is for further development, possibly other than the one for the realization of a solid residue deposit;

- the existing climatic conditions and how they can be changed, at the local level, by placing the residue depot;

- $\quad$ how and the extent to which groundwater can be affected;

- the costs of the transport of the residues, to the place of their storage.

Regardless of whether the landfill is surface or located in a natural depression, the landfill must be dry before storage, with a solid content of more than $85 \%$. Drying simplifies the transport of residues, allows easier distribution in the warehouse, and more compact compaction, the density of the deposited material can reach $85 \div 95 \%$ of the maximum density of solid waste.

During periods when the boiler is switched off (during the hot season, if it is a district heating plant) or when an energy block is in reserve, the ash hydro transport pipes can be used to wet the surface of the depot through two or three holes. spill. The operation of the flood system must be carried out carefully, by permanently changing the position of the spillways, to avoid the formation of water mesh, which may endanger the stability of the deposit. A part of the fine ash, separated by the electrophiles, can be mixed with water, in a ratio of 1: 1, the dense fluid thus obtained, being able to be disposed on the surface of the deposit.

Thus, hardened layers are formed, whose thickness is of the order of $15 \div 20 \mathrm{~cm}$, and which is characterized by good stability. In this final stage, three types of operations are performed: final compaction and leveling, to ensure drainage; placement of infiltration barriers; coating with a vegetal soil layer, and anti-erosion seeding [12]. 


\section{Conclusions}

Power plants face major environmental problems, the solution to which depends on obtaining an environmental permit to operate under the conditions imposed by the European Union. Romania, in the effort to join the European Union, has established the environmental protection strategy, the priority directions for energy.

As measures to prevent environmental pollution are the following:

- use of coal and low-sulfur fuel;

- increasing the efficiency of electricity production through rehabilitation and modernization works;

- improving the combustion control and regulation processes, with the completion of maintenance, rehabilitation and modernization works;

- increasing the performance of electro filters;

- introduction of burners with low $\mathrm{N}$ emissions;

- installation of desulphurization systems;

- improving energy-environment management;

- elimination of advanced, physical, and moral wear and tear installations.

\section{References}

[1] L.F. DRBAL, P.G. BOSTON, K.L. WESTRA, R.B. ERIKSON, Power plant engineering, by Black \& Veatch, Chapman \& Hall, International Thomson Publishing Company, (1996).

[2] O. BLĂGOI, E.L. PUŞCAŞ, Surface water treatment - chemical methods, Editura Dosoftei, Iaşi, (1997).

[3] G.M. MASTERS, Introduction to Environmental Engineering and Science, PrenticeHall, Englewood Cliffs, New Jersey, (1991).

[4] B.T. RAY, Environmental Engineering, PWS Publishing Company, An International Thomson Publishing Company, Boston, (1995).

[5] C.A. WENTZ, Hazardous Waste Management, McGraw-Hill, New York, (1989).

[6] H.M. FREEMAN, ed., Standard Handbook of Hazardous Waste Treatment and Disposal, McGrawHill, New York, (1989).

[7] E.J. HALLER, Simplified Wastewater Treatment Plant Operations, Technocomic Publishing Company, Lancaster, Pennsylvania, (1995).

[8] H.S. PEAVY, D.R. ROWE, G. TCHOBANOGLOUS, Environmental engineering, McGraw-Hill, (1985).

[9] P.A. VESILING, J.J. PIERCE, R.F. WEINER, Environmental engineering-Third Edition, McGraw Hill, (1993).

[10] M.D. BROWN, T.D. WENCE, T.C. REILLY, Solid Waste Transfer Fundamentals, Ann Arbor Science, Ann Arbor, Michigan, (1980).

[11] A.P. SINCERO, G.A. SINCERO, Environmental Engineering-A Design Approach, Prentice-Hall Inc., (1996).

[12] D.C. WILSON, Waste Management: Planning, Evaluation, Technologies, Clarendon Press, Oxford, England, (1981). 